Book chapter published in: 'Writing Development in Children with Hearing Loss, Dyslexia, or Oral Language Problems.' (2014). B. Arfe, J. Dockrell and V. Berninger (Eds.), DOI:10.1093/acprof:oso/9780199827282.001.0001

\title{
Chapter 14. A Review of Dyslexia and Expressive Writing in English
}

\author{
Emma Sumner ${ }^{\mathrm{a}}$, Vincent Connelly ${ }^{\mathrm{b}}$ \\ and \\ Anna L. Barnett ${ }^{\mathrm{b}}$ \\ ${ }^{a}$ Department of Psychology; Goldsmiths, University of London \\ ${ }^{\mathrm{b}}$ Department of Psychology; Oxford Brookes University.
}

Corresponding author:

Emma Sumner

Department of Psychology

Goldsmiths, University of London

New Cross

London, SE14 6NW

UK

e.sumner@gold.ac.uk 


\begin{abstract}
Children and adults with dyslexia struggle with reading and accurate spelling. Spelling is a key component of the writing process. Therefore, it is conceivable that the difficulties individuals with dyslexia experience in this area will impact on the development and efficiency of the writing process in some way. This chapter provides a review of the current literature that has attempted to profile the writing skills of individuals with dyslexia. Areas of study include writing quality, the role of reading and spelling when writing, vocabulary and handwriting. Findings across studies largely demonstrate that individuals with dyslexia are poorer writers in comparison to their age-matched peers. It is suggested that poor spelling may explain performance. This chapter concludes with possible avenues for future research; namely to consider the process of written production in order to accurately identify the nature of writing difficulties.
\end{abstract}

Keywords: dyslexia, handwriting, language, spelling, vocabulary, writing. 


\section{Introduction}

Considerable advances have been made in understanding the cognitive processes underlying reading and spelling problems in individuals with dyslexia. However there has been much less work on issues related to their writing. Writing is a more difficult skill as it involves production as well as processing of print and poor writing is a barrier to educational progress. In fact adults with dyslexia report that writing, not reading, is their biggest problem (Burden, 2005; Mortimore \& Crozier, 2006). Public school exams are traditionally weighted towards assessment based on producing extended written responses. It has been shown that students with dyslexia achieve lower levels of success in exams than their peers (Richardson \& Wydell, 2003); while a large sample of poor readers identified in a childhood sample continued to have poor spelling in their mid adult life and $80 \%$ of the sample reported difficulty with writing a letter or filling in a form (Maughan, Messer, Collishaw, Snowling, Yule, \& Rutter, 2009). Although very high achieving university students with dyslexia studying medicine do appear to do as well as other students on exams including writing short answers (McKendree \& Snowling, 2011), even in this population there are some persisting difficulties with written assessments and adults with dyslexia do better with extra time in exams (Gibson \& Leinster, 2011).

\section{Definition of Dyslexia in English}

Dyslexia is a developmental disorder characterised by a specific word-level deficit (Berninger, Nielsen, Abbott, Wijsman, \& Raskind, 2008; Nation, 2011) and so there has been much speculation about the overlap between dyslexia and children with oral language difficulties (Catts, 1996; Hulme \& Snowling, 2009). However, a number of thorough reviews (Bishop \& Snowling, 2004; Catts, Adolf, Hogan, \& Weismer, 2005; Nation, 2011; Pennington \& Bishop, 2009) have made a clear claim that children with dyslexia are distinct 
from those with wider language problems such as specific language impairment (SLI). Therefore, we shall concentrate here on those individuals who have been identified with dyslexia only and whose dyslexia is not symptomatic of a wider oral language difficulty. In the UK, there have been many different definitions of dyslexia (Brooks, 2007). The varied use of these definitions has led to many heated debates not just in academia or education but more widely in Government and the media. In response to this debate the UK government commissioned a report into the identification and teaching of young people and children with dyslexia and literacy difficulties. The Rose report (2009) provided a working definition of dyslexia in the UK context that is reproduced in full below:

"Dyslexia is a learning difficulty that primarily affects the skills involved in accurate and fluent word reading and spelling. Characteristic features of dyslexia are difficulties in phonological awareness, verbal memory and verbal processing speed. Dyslexia occurs across the range of intellectual abilities. It is best thought of as a continuum, not a distinct category, and there are no clear cut-off points. Co-occurring difficulties may be seen in aspects of language, motor co-ordination, mental calculation, concentration and personal organisation, but these are not, by themselves, markers of dyslexia. A good indication of the severity and persistence of dyslexic difficulties can be gained by examining how the individual responds or has responded to well-founded intervention.” (Rose, 2009, p.30)

This definition, while still stirring up some controversy was generally well received by the academic and educational communities of interest in the UK. However, in practice many assessments made in schools still rely on distinct cut off points and tie the diagnosis to a discrepancy between reading and IQ (Bell, McPhillips, \& Doveston, 2011). There have been similar debates proposed in the USA (Lyon, Shaywitz, \& Shaywitz, 2003). 
English speaking children with dyslexia will usually show difficulties in developing appropriate levels of accuracy, as well as fluency, when reading and spelling words. On average, they are less accurate and slower at reading single words and they are invariably even poorer at spelling the same words (see Hulme \& Snowling, 2009). A large and complex literature has shown that the majority of children with dyslexia have difficulties with the phonological aspects of reading and spelling in English (Hulme \& Snowling, 2009; Kemp, 2009), but a growing literature points to learning problems related to orthography as well as phonology in dyslexia (de Jong \& Messbauer, 2011; Nation, 2011; Snowling, 2011). The coding of phonological information in memory and the transformation of phonological information into orthographic codes (written words) is difficult for these children (Berninger et al., 2008; Gayan \& Olson, 2001). Many individuals with dyslexia also have problems with rapid naming of letters (Jones, Branigan, \& Kelly, 2009) and working memory spans appear to be smaller (Gathercole, Alloway, Willis, \& Adams, 2006). However, most researchers argue that the difficulties faced by children with dyslexia when dealing with print have their impact specifically at the word or sub-word level (Jackson \& Coltheart, 2001). These wordlevel deficits then in turn will affect processing at other levels of written language.

\section{The Writing Profile of English Speaking Children with Dyslexia}

The review above shows that there are a number of reasons to predict that children diagnosed with dyslexia in English would experience difficulties with writing. When examining the composition of English speaking individuals with dyslexia a number of differences from their peers are quickly noticed. First of all, they contain many more spelling errors than essays produced by other individuals of the same age (Coleman, Gregg, McLain $\&$ Bellair, 2009). It is also no surprise that the compositions are shorter and are rated more poorly in both content and organization than their peers without dyslexia (Connelly, 
Campbell, MacLean, \& Barnes, 2006; Gregg, Coleman, Davis and Chalk, 2007; Sterling, Farmer, Riddick, Morgan, \& Matthews, 1998). Furthermore, there are reports that they are very slow writers (British Dyslexia Association, 2011; Rose, 2009); and motivation to write in these children may also be a key issue when faced with a more difficult task than their peers (Berninger \& Hidi, 2007; Graham, Berninger, \& Fan, 2007).

\section{Problems with Reading?}

Reading is a critical skill for a writer (Juel, 1988). Reading develops the complex vocabulary, written grammatical knowledge and the appropriate background context to draw upon when composing and allows for rapid reviewing of the written text. Reading back and forth through the text when writing has been shown to be a common occurrence for typically achieving children and adults (Wengelin, Leijten \& Van Waes, 2010) and re-reading has been associated with increased text quality (Breetvelt, Van den Bergh, \& Rijlaarsdam, 1996); but ironically slower writers appear to need to rely on reading more when writing than more fluent writers (Beers, Quinlan, \& Harbaugh, 2010). Furthermore, strong links between reading comprehension and writing skills have been shown to grow through the primary school years (Bourke \& Adams, 2010; Juel, 1988). Thus, difficulty with reading acquisition has consequences for both vocabulary growth and reading comprehension, since the struggle to recognise words will hinder sufficient practice in developing comprehension skills (Cain, 2009; Carlisle \& Rice, 2002). Therefore, difficulties with reading will impact on the development of writing, in particular spelling (see below), thus leading to a delayed writing profile.

However, reading and writing are separable processes and are likely to interact differently at different developmental stages (Abbott, Berninger, \& Fayol, 2010; Shanahan, 2006). This complicates matters and while reading and writing are strongly correlated, 
reading is rarely reported to account for more than $50 \%$ of the variance in writing at any one point in development (Fitzgerald \& Shanahan, 2000; Shanahan, 2006). Therefore, it is reasonable to propose that the writing difficulties of children with dyslexia may be limited to specific areas around spelling, vocabulary and the "lower level" writing processes. In fact, a study of high achieving university students with dyslexia showed no difference in higher order writing skills such as essay organisation and coherence compared to same age peers when writing essays but while still producing many more of the spelling errors that are typical of those with dyslexia (Connelly, et al, 2006). There have been no carefully controlled intervention studies that have shown direct effects of reading interventions on the development of writing skill in children with dyslexia that we have found to date.

\section{Problems with Spelling?}

A major difficulty that children with dyslexia have when beginning to learn to write is learning to spell. Their poor phonological skills inhibit the development of orthographic knowledge (Fayol, Zorman, \& Lete, 2009). Children with dyslexia find it difficult to make associations and store representations of word-specific spelling conventions (Bruck, 1993; Olson, Wise, Johnson, \& Ring, 1997). This is particularly true in the English language where spellings are often irregular and these conventions must be learned implicitly (Moats, 1995; Tsesmeli \& Seymour, 2006). There are also strong frequency and consistency effects in learning to spell in English that will be accentuated by poorer and thus less frequent reading (Nation, Angell, \& Castles, 2007). Children with dyslexia continue to have difficulty with spelling even when their problems in reading words seem to have resolved (Kemp, Parilla \& Kirby, 2009) and the essays of students with dyslexia contain many more spelling errors compared to typically achieving age-matched peers (Connelly et al., 2006; Sterling et al., 1998). 
Misspelling can also have a direct influence on ratings of text quality (Berninger, Vaughan, Abbott, Begay, Byrd et al., 2002). Spelling is a key predictor of writing composition quality in both typical children and in children with dyslexia up to the age of 11, and even beyond (Abbott et al., 2010; Berninger et al., 2008; Gregg et al., 2007). Good spellers use fluent and efficient strategies to spell while poor spellers are slow and effortful in their spelling (Rittle-Johnson \& Siegler, 1999). Having to concentrate on spelling words takes time away from the purpose of writing and means less text is produced in the equivalent time to those without spelling problems (Connelly et al., 2006; Gregg et al., 2007) and there is an increasing link between text length and text quality as children and adults make progress in writing (Berninger \& Swanson, 1994; Gregg, Coleman, Stennett, \& Davis, 2002).

Over time, the constraints on writing from transcription exert less influence on text quality in typically developing children and they are able to devote more resources to higherorder cognitive processes (Berninger \& Swanson, 1994), but children with dyslexia persist in their struggle with spelling (Puranik, Lombardino, \& Altmann, 2007; Sumner, Connelly \& Barnett, 2013). Spelling interventions have achieved some success with children diagnosed with dyslexia (see Brookes, 2007) and improvements in spelling can lead to improvements in written composition (Berninger et al., 2002). Thus a large part of the difficulty that children with dyslexia have with writing could be partly dealt with through specific spelling interventions that will then have indirect effects through to improved compositional development.

\section{Does poor spelling influence vocabulary choice and grammar when writing text?}

Vocabulary knowledge requires both phonological and semantic representations and is heavily related to amounts of reading experience (Wise, Sevcik, Morris, Lovett, \& Wolf, 2007). Vocabulary levels are likely to be slightly delayed in children with dyslexia due to 
reduced reading exposure. This may in turn have a detrimental effect on ratings of written work, since a high graded text is typically associated with a higher level of lexical diversity and sophisticated grammatical constructions (Grobe, 1981; Olinghouse \& Leaird, 2009).

There has been very little work on written vocabulary choice in children with dyslexia. Quotes such as: "Many participants in our research studies lament that they cannot write compositions that express their ideas without limiting those ideas to the words they think they can spell without embarrassment." (Berninger et al, 2008. p.17) are common in the literature but actual studies examining this issue are still quite rare. Research in Swedish appears to show a link between spelling and vocabulary choice. It was found that adults with dyslexia showed lower lexical diversity and density in their written language but not in their spoken language when compared to their peers (Wengelin, 2007).

Sterling et al (1998) analysed the syllable length of vocabulary choices made in a free writing task completed by English-speaking university students with and without dyslexia. Students with dyslexia used many one-syllable words, rarely using words consisting of up to three syllables. Their age-matched peers, however, used proportionally more words of three syllables and longer. By way of contrast, Connelly et al. (2006) found no difference in lexical diversity between a sample of UK students with dyslexia and a chronological age matched group when a timed more complex expository writing task was rated. This study used a more difficult writing task than did Sterling et al (1998) and so the two studies suggests that when given an easier writing task the individual with dyslexia may choose easier to spell vocabulary but when faced with a task where complex language is required then they do respond to the task vocabulary requirements. The essays produced in the Connelly et al. (2006) study were complex and showed appropriate use of low frequency words where required. Thus, conflicting results from studies in English means that it still remains open to 
debate whether poor spelling contributes to constrained written vocabulary choices in individuals with dyslexia.

A study of individuals with dyslexia between the ages of 11 and 21 used a 'writing through retelling' task and found no difference in lexical diversity between those with dyslexia and age matched controls (Puranik et al., 2007). Rather, a third group of children with more general language impairment had poorer lexical diversity. However, these children with dyslexia produced as many grammatically incorrect sentences as the language impaired group. Although these findings are intriguing, scoring of the syntactic errors of the sentences may have included counting errors in inflexional morphology. Inflexional morphology is a specific spelling weakness for individuals with dyslexia (Joanisse, Manis, Keating, \& Seidenberg, 2002); therefore, the report of syntactic problems from the Puranik et al. (2007) study may be compounded by their spelling difficulties.

\section{Problems with handwriting?}

Another reported difficulty children with dyslexia face when writing may be related to handwriting skill. Speed of handwriting is a strong predictor of written composition length and quality in typically developing children and even in some adults (Berninger and Swanson, 1994; Connelly, Dockrell \& Barnett, 2005; Graham, Berninger, Abbott, Abbott, \& Whitaker, 1997). Berninger et al. (2008) recruited a sample of 122 children with dyslexia and tested them on a range of measures, including handwriting automaticity (using an alphabet writing task). Although no comparison group was used the results did indicate that children were impaired in handwriting speed (1.1 SD below the mean of Graham et al., 1997) but that neither handwriting speed nor motor skills predicted written composition quality while spelling skill did. Other studies (using different tasks) also appear to show that the handwriting of children with dyslexia is slower than peers (Sovik \& Arntzen, 1986; Sovik, 
Arntzen \& Thygesen 1987) and continues to be slower in adulthood (Hatcher, Snowling, \& Griffiths, 2002). However, some studies have found no evidence of handwriting speed differences for children with dyslexia compared to their peers (Martlew, 1992) and while there may be differences in handwriting speed in adulthood this may not differ from equivalent spelling-ability matched controls (Connelly et al., 2006).

A pattern of mixed results is not uncommon in dyslexia research due to the different tasks used to measure the same activity. The handwriting tasks undertaken have also included speeded writing and there is evidence that many, but not all, children with dyslexia have problems with speeded tasks generally (Katzir, Kim, Wolf, O’Brien, Kennedy et al., 2006). Therefore, the mixed picture regarding handwriting speed could be explained by individual differences in speed of accessing letter like forms in memory and integrating those with hand movements to produce letters. Speed of accessing letters in a RAN task was found to be predictive of writing quality in a sample of eleven-year-old children with dyslexia (Berninger et al, 2008). Letter knowledge is highly predictive of spelling in the early years of schooling in English (Muter, Hulme, Snowling, \& Stevenson, 2004) and children with dyslexia are slower at developing letter knowledge (Nation, 2011).

With reported incidences of movement difficulties in dyslexia (Iversen, Berg, Ellertsen, \& Tonnessen, 2005) and co-morbidity with developmental co-ordination disorder (DCD) (Chaix, Albaret, Brassard, Cheuret, Castelnau et al, 2007), it is possible that slow handwriting may be a direct consequence of poor motor control and coordination. It is rare for motor performance to be separately assessed or DCD considered in studies of writing in children with dyslexia. In our own work, when general motor difficulty has been ruled out, handwriting has still been found to be slow. However, detailed analysis of the writing task, using a digital writing tablet, demonstrated that the actual movement of the pen to form letters was as fast as age matched peers (Sumner, Connelly \& Barnett, 2011, 2013). 
Another explanation for slow writing in samples with dyslexia may be more directly related to spelling. If children with dyslexia are struggling with spelling, they may show more pauses in writing to try and process the spellings of words. If so, then they slow down the process of transcription, leading to slower writing than would be expected. It has been demonstrated in keystroke logged essays in Swedish that adults with dyslexia produce more pauses overall and in particular more inter-word pauses than age-matched controls (Wengelin, 2007; Wengelin \& Stromqvist, 2000).

Using a digital writing tablet, it has also been recently demonstrated that a sample of children with dyslexia paused more frequently during writing and were slower at composing a text than age-matched peers. As mentioned above, however, the speed of the pen on the page was identical to peers while the amount of time pausing was the same as spelling ability-matched children (Sumner et al., 2011, 2012). Therefore, it seems that the pure writing speed of children with dyslexia is not slow in itself but when required to spell while writing, more frequent pausing slows the overall writing process down. Handwriting is constrained by spelling. These are important findings, demonstrating that more frequent pausing and not writing speed may be the real issue behind the slower pace of handwriting in children with dyslexia. These findings need to be more widely investigated and taken into account when modelling the development of writing.

\section{Looking ahead}

This review has shown that children with dyslexia have difficulty learning to write. This difficulty appears to be primarily driven by the children's difficulties with word and subword level learning. This has an impact on their ability to interweave reading and writing processes leading to a severe impact on spelling, the slowing down of composing and an impact on vocabulary diversity when composing. We suspect there is less evidence for a clear 
handwriting problem and the slower pace of writing in children with dyslexia may be mediated by problems with pausing to spell. However, given the specificity of the problems faced by children with dyslexia the prognosis for remediation remains good. Interventions to support spelling have been shown to impact on written expression. These interventions take a lot of time and effort (Berninger et al., 2002) but could prove to support the composing skills of children with dyslexia.

One reason for the current lack of depth in understanding has been the difficulty in measuring what aspects of writing children are actually struggling with. Research on text production in children with writing difficulties has usually been limited to a focus on products/outputs at single points in time (see special edition Reading \& Writing 2008 Vol1/2) not the process of production. The tools needed to measure process have, until recently, either involved oral protocols or complex cognitive tasks in school contexts, or are required to be conducted in experimental laboratories. These methods, while sound in principle, are not ideal for examining process in primary school aged children. Thus, the majority of the research on writing and dyslexia has taken place with adults not children.

Recent work has shown through using real time data from portable digital writing tablets that typically developing children's spelling and handwriting processes are intimately linked at the level of the within-word syllable (Kandel, 2009). Kandel demonstrated that the spelling of a word is produced syllable by syllable and that children prepare the movement to produce the first syllable before starting to write. The child then begins to program in parallel the movement to produce the second syllable on-line, while still engaged in writing the first few letters. Kandel's work has also shown that other levels of language are important to the spelling of a word such as the initial morpheme and the selection of the appropriate grapheme. This ties in well with our recent work showing the importance of analysing the 
detailed writing processes of children with dyslexia (Connelly et al., 2011; Sumner et al., 2013).

This micro-study of writing has very important implications for the study of children with dyslexia. For example, it may be that to write a word most efficiently the child requires the ability to chunk that word into syllables. It is known that children with dyslexia have difficulty with the segmentation of word spellings. Thus, it will be important to demonstrate how and at what level children with dyslexia are similar to the typically developing children sampled in Kandel's work.

It is also very important to look at the impact of the spelling patterns of different written languages. French is (like Spanish) a more syllabically based written language than English and so one could make different predictions about the level of chunking required to write English spellings efficiently. Thus, a breakdown in spelling could take place at different linguistic levels (e.g, morpheme, syllable, grapheme etc) when children struggle with writing in different languages.

Finally, the ability to process complex linguistic information in typically developing children requires an efficient working memory system. As shown in Berninger and Swanson's (1994) developmental model of the writing processes, working memory regulates the recursive processes engaged while writing and responds to specific task needs. A limited working memory capacity has been found in children with dyslexia (Gathercole et al., 2006). Although under-researched at present these limited memory resources along with the high cognitive cost of spelling irregularities (Fayol, 1999) in the English language may disrupt the high-order processes, such as idea generation and word selection, and the lower-level transcription skills. Further study into the detailed links between language, spelling and handwriting will allow us to understand the processes that compete for resources in these children when writing. 


\section{References}

Abbott, R., Berninger, V., \& Fayol, M. (2010). Longitudinal relationships of levels of language in writing and between writing and reading in grades 1 to 7 . Journal of Educational Psychology, 102, 281-298.

Beers, S. F., Quinlan, T., \& Harbaugh, G. (2010). Adolescent students' reading during writing behaviors and relationships with text quality: An eyetracking study. Reading and Writing: An Interdisciplinary Journal, 23, 743-775.

Bell, S., McPhillips, T., \& Doveston, M. (2011) How do teachers in Ireland and England conceptualise dyslexia? Journal of Research in Reading. Early View no. doi: 10.1111/j.1467-9817.2009.01419.x

Berninger, V. W., \& Hidi, S. (2007). Mark twain's writers' workshop: A nature-nurture perspective for motivating students with learning disabilities to compose. In S. Hidi, \& P. Boscolo (Eds.), Writing and motivation (pp. 163-182). Bingley, UK: Emerald.

Berninger, V. W., \& Swanson, H. L. (1994). Modifying Hayes and Flower's Model of Skilled Writing. In E. Butterfield (Ed.), Children's Writing; Toward a Process Theory of Development of Skilled Writing (pp. 57-81). Greenwich, CT: JAI Press.

Berninger, V. W., Nielsen, K. H., Abbott, R. D., Wijsman, E., \& Raskind, W. (2008). Writing problems in developmental dyslexia: Under-recognized and under-treated. Journal of School Psychology, 46, 1-21.

Berninger, V., \& Swanson, H.L. (1994). Modifying Hayes \& Flower's model of skilled writing to explain beginning and developing writing. In E. Butterfield (Ed.), 
Children's writing: Toward a process theory of development of skilled writing (pp. 57-81). Greenwich, CT: JAI Press.

Berninger, V., Vaughan, K., Abbott, R., Begay, K., Byrd, K., Curtin, G., Minnich, J., \& Graham, S. (2002). Teaching spelling and composition alone and together: Implications for the simple view of writing. Journal of Educational Psychology, 94, 291-304.

Bishop, D. V. M., \& Snowling, M. J. (2004). Developmental Dyslexia and Specific Language Impairment: Same or Different? Psychological Bulletin, 130, 858-886.

Bourke, L., \& Adams, A-M. (2010). Cognitive constraints and the Eary Years; Learning Goals in writing. Journal of Research in Reading, 33, 94-110.

Breetvelt, I., Van den Bergh, H., \& Rijlaarsdam, G. (1996). Rereading and generating and their relation to text quality: An application of multilevel analysis on writing process data. In G. Rijlaarsdam, H. Van, F. den Bergh, \& M. Couzijn (Eds.), Theories, models, and methodology in writing research: Studies in writing (Vol. 1, pp. 10-20). Amsterdam: Amsterdam University Press.

British Dyslexia Association (2011). Information for Parents: Help with Handwriting. Retrieved July 28, 2011, from http://www.bdadyslexia.org.uk/aboutdyslexia/parents/help-with-handwriting.html.

Brooks, G. (2007). What works for pupils with literacy difficulties? London: DCSF.

Bruck, M. (1993). Component spelling skills of college students with childhood diagnoses of dyslexia. Learning Disabilities Quarterly, 16, 171-184.

Burden, R. (2005). Dyslexia and Self-Concept: Seeking a dyslexic identity. London: Whurr. Cain, K. (2009). Childen's reading comprehension difficulties: a consideration of the precursors and consequences. In C. Wood \& V. Connelly (Eds). Contemporary perspectives on reading and spelling (pp. 76-91). United Kingdom, Routledge. 
Carlisle, J.F. \& Rice, M.S. (2002). Improving Reading Comprehension, Research-Based Principles and Practices. York Press, Inc., Timonium.

Catts, H. W. (1996). Defining dyslexia as a developmental language disorder: An expanded view. Topics in Language Disorders, 16, 14-29.

Catts, H. W., Adolf, S. M., Hogan, T. P., \& Weismer, S. E. (2005). Are Specific Language Impairment and Dyslexia Distinct Disorders? Journal of Speech, Language, and Hearing Research, 48, 1378-1396.

Chaix, Y., Albaret, J.-M., Brassard, C., Cheuret, E., Castelnau, P., Benesteau, J., et al. (2007). Motor impairments in dyslexia: The influence of attention disorders. European Journal of Paediatric Neurology, 11, 368 - 374.

Coleman, C., Gregg, N., McLain, L. \& Bellair, L.W. (2009). A comparison of spelling performance across young adults with and without dyslexia. Assessment for effective Intervention, 34, 94-105.

Connelly, V, Dockrell, J.E., Barnett, A. (2011). Children Challenged by Writing Due to Language and Motor Difficulties. In V. Berninger (Ed.) Cognitive Psychology of Writing Handbook: Past, Present, and Future Contributions of Cognitive Writing Research to Cognitive Psychology. (pp. 217-245). New York, Psychology Press.

Connelly, V. Dockrell, J., Barnett, J. (2005). The slow handwriting of undergraduate students constrains overall performance in exam essays. Educational Psychology, 25, 99-107.

Connelly, V., Campbell, S., MacLean, M., \& Barnes, J. (2006). Contribution of lower order skills to the written composition of college students with and without dyslexia. Developmental Neuropsychology, 29, 175-196.

de Jong P \& Messbauer V (2011). Orthographic Context and the Acquisition of Orthographic Knowledge in Normal and Dyslexic Readers. Dyslexia. 17, 107-122. 
Fayol, M., Zorman, M., \& Lété, B. (2009). Associations and dissociations in reading and spelling French. Unexpectedly poor and good spellers. British Journal of Educational Psychology, 6, 63-75.

Fitzgerald, J., \& Shanahan, T. (2000). Reading and writing relations and their development. Educational Psychologist, 35, 39-50.

Gathercole, S.E., Alloway, T.P., Willis, C.S., \& Adams, A.M. (2006). Working memory in children with reading disabilities. Journal of Experimental Child Psychology, 93, 265281.

Gayan, J., Olson, R. K. (2001). Genetic and environmental influences on orthographic and phonological skills in children with reading disabilities. Developmental Neuropsychology, 20(2), 483-507.

Gibson, S and Leinster, SJ (2011) How do students with Dyslexia Perform in Extended Matching Questions, Short Answer Questions and Observed Structured Examinations? Advances in Health Science Education Theory and Practice, 16, 395404.

Graham, S., Berninger, V. W., \& Fan, W. (2007). The structural relationship between writing attitude and writing achievement in first and third grade students. Contemporary Educational Psychology, 32, 516-536.

Graham, S., Berninger, V. W., Abbott, R. D., Abbott, S. P., \& Whitaker, D. (1997). Role of mechanics in composing of elementary school students. A new methodological approach. Journal of Educational Psychology, 89, 170-182.

Gregg, N. G., Coleman, C., Davis, M., \& Chalk, J. C. (2007). Timed Essay Writing: Implications for High-Stakes Test. Journal of Learning Disabilities 40, 306 - 318. 
Gregg, N., Coleman, C., Stennett, B., \& Davis, M. (2002). Discourse complexity of college writers with and without disabilities: A multidimensional analysis. Journal of Learning Disabilities, 35, 23-38.

Grobe, C. (1981). Syntactic maturity, mechanics, and vocabulary as predictors of quality ratings. Research in the Teaching of English, 15, 75-85.

Hatcher, J., Snowling, M.J., \& Griffiths, Y.M. (2002). Cognitive assessment of dyslexic students in higher education. British Journal of Educational Psychology. 72, 119-133.

Hulme, C.J. \& Snowling, M.J. (2009). Developmental disorders of language learning and cognition. Oxford. Blackwell/Wiley.

Iversen, S., Berg, K., Ellertsen, B., \& Tonnessen, F-E. (2005). Motor coordination difficulties in a municipality group and in a clinical sample of poor readers. Dyslexia, 11, 217231.

Jackson, N. E., \& Coltheart, M. (2001). Routes to reading success and failure. New York: Psychology Press.

Joanisse, M. F., Manis, F. R., Keating, P., \& Seidenberg, M. S. (2000). Language deficits in dyslexic children: Speech perception, phonology and morphology. Journal of Experimental Child Psychology, 77, 30-60.

Jones, M. W., Branigan, H. P., \& Kelly, M. L. (2009). Dyslexic and nondyslexic reading fluency: Rapid automatized naming and the importance of continuous lists. Psychonomic Bulletin \& Review, 16(3), 567-572.

Juel, C. (1988). Learning to read and write: A longitudinal study of 54 children from first through fourth grades. Journal of Educational Psychology, 80, 437-447.

Kandel, S. (2009). For a psycholinguistic approach of handwriting production. In A. Vinter \& J.L. Velay (Eds), Proceedings of the $14^{\text {th }}$ Conference of the International Graphonomics Society, 83-86. Universite de Bourgogne Press. 
Katzir, T., Kim, Y., Wolf, M., O'Brien, B., Kennedy, B., Lovett, M., et al. (2006). Reading fluency: The whole is more than the parts. Annals of Dyslexia, 56, 51-82.

Kemp, N. (2009). The acquisition of spelling patterns: early, late or never? In C. Wood \& V. Connelly (Eds). Contemporary perspectives on reading and spelling (pp. 76-91). United Kingdom, Routledge.

Kemp, N., Parrila, R., \& Kirby, J., (2009). Phonological and orthographic spelling in highfunctioning adult dyslexics. Dyslexia, 15, 105-128

Lyon, G. R., Shaywitz, S. E., \& Shaywitz, B. A. (2003). Defining Dyslexia, Comorbidity, Teachers' Knowledge of Language and Reading. A definition of Dyslexia. Annals of Dyslexia, 53, 1-14.

Martlew, M. (1992). Handwriting and spelling - Dyslexic children's abilities compared with children of the same chronological age and younger children of the same spelling level. British Journal of Educational Psychology, 62, 375-390.

Maughan, B., Messer, J., Collishaw, S., Snowling, M.J., Yule, W., Rutter, M. (2009). Persistence of literacy problems: spelling in adolescence and at mid-life. Journal of Child Psychology \& Psychiatry, 50, 893-901.

McKendree, J., \& Snowling, M.J. (2011). Examination results of medical students with dyslexia. Medical Education, 45, 176-182.

Moats, L. C. (1995). Spelling: Development, disabilities, and instruction. Timonium, MD: York Press.

Mortimore, T., \& Crozier, W. R. (2006). Dyslexia and difficulties with study skills in higher education. Studies in Higher Education, 31, 235-251.

Muter, V., Hulme, C., Snowling, M. J., \& Stevenson, J. (2004). Phonemes, rimes and language skills as foundations of early reading development: Evidence from a longitudinal study. Developmental Psychology, 40, 665-681. 
Nation, K. (2011). Disorders of reading and writing. The Cambridge Encyclopaedia of the Language Sciences.

Nation, K., Angell, P. \& Castles, A. (2007). Orthographic learning via self-teaching in children learning to read English: effects of exposure, durability and context. Journal of Experimental Child Psychology, 96, 71-84.

Olinghouse, N. G., \& Leaird, J. L. (2009). The relationship between measures of vocabulary and narrative writing quality in second- and fourth-grade students. Reading and Writing, 22, 545-565.

Olson, R. K., Wise, B., Johnson, M. C., \& Ring, J. (1997). The etiology and remediation of phonologically based word recognition and spelling difficulties : Are phonological deficits the 'hole' story? In B. Blachman, (Eds). Foundations of reading acquistion and dyslexia : implications for early intervention. (pp. 305-326) Hillsdale, NJ : Lawrence Erlbaum Associates

Pennington, B. F. \& Bishop, D. V. M. (2009). Relations among speech, language and reading disorders. Annual Review of Psychology, 60, 283-306.

Puranik, C. S., Lombardino, L. J., \& Altmann, L. J. P. (2007). Writing through retellings: an explanatory study of language-impaired and dyslexic populations. Reading and Writing, 20, $251-272$.

Richardson, J.T.E. and Wydell, T.N. (2003) The representation and attainment of students with dyslexia in UK higher education, Reading and Writing: An Interdisciplinary Journal, 16, 475-503.

Rittle-Johnson, B., \& Siegler, R. S. (1999). Learning to spell: Variability, choice, and change in children's strategy use. Child Development, 70, 332-348.

Rose, J. (2009) Independent review of the Primary curriculum, Nottingham: DCSF. 
Shanahan, T. (2006). Relations among oral language, reading and writing development. In C. MacArthur, S. Graham, \& J. Fitzgerald (Eds.), Handbook of writing research (pp. 171-183). New York: Guilford.

Snowling, M.J. (2011). What places a child at risk of dyslexia? Evidence from family risk studies. Keynote address at the British Dyslexia Association: Beyond Boundaries Harrogate International Conference Centre, 2nd June 2011.

Sovik, N., \& Arntzen, O. (1986). A comparative study of the writing/spelling performances of 'normal', dyslexic, and dysgraphic children. European Journal of Special Needs Education 1(2), 85-101.

Sovik, N., Arntzen, O., \& Thygesen, R. (1987). Writing characteristics of normal, dyslexic and dysgraphic children. Journal of Human Movement Studies, 13(4), 171-187.

Sterling, C., Farmer, M., Riddick, B., Morgan, S., \& Matthews, C. (1998). Adult Dyslexic Writing. Dyslexia, 4, 1-15.

Sumner, E., Connelly, V., \& Barnett, A. (2011). Writing performance of children with dyslexia. Paper presented at the British Dyslexia Association: Beyond Boundaries Harrogate International Conference Centre, 2nd June 2011.

Sumner, E., Connelly, V., \& Barnett, A. (2013). Children with dyslexia are slow writers because they pause more often and not because they are slow at handwriting. Reading and Writing: An Interdisciplinary Journal, 26(6), 991-1008.

Tsesmeli, S. N., \& Seymour, P. H. K. (2006). Derivational morphology and spelling in dyslexia. Reading and Writing, 19, 587-625.

Wengelin, A. (2007). The Word-Level Focus in Text Production by Adults with Reading and Writing Difficulties. In Gert Rijlaarsdam (Ed.) Writing and cognition (Studies in Writing, Volume 20), Emerald Group Publishing Limited, pp.68-82. 
Wengelin, A., \& Stromqvist, S. (2000). Discourse level writing in dyslexics--methods, results, and implications for diagnosis. Logopedics, Phoniatrics, Vocology, 25(1), 2228.

Wengelin, A., Leijten, M., \& Van Waes, L. (2010). Studying reading during writing: New perspectives in research. Reading and Writing: An Interdisciplinary Journal, 23,735742.

Wise, J. C., Sevcik, R. A., Morris, R. D., Lovett, M. W., \& Wolf, M. (2007). The Relationship Among Receptive and Expressive Vocabulary, Listening Comprehension, Pre-Reading Skills, Word Identification Skills, and Reading Comprehension by Children With Reading Disabilities Journal of Speech, Language, and Hearing Research, 50, 1093-1109. 